\title{
Petrografia e caracterização tecnológica dos gnaisses enderbíticos da porção norte do estado do Ceará com aplicação no setor de rochas ornamentais
}

\author{
Anna Paula Lima Costa ${ }^{1,2}$, José de Araújo Nogueira Neto ${ }^{3}$ \& Tamar Milca Bortolozzo Galembeck ${ }^{1}$
}

\begin{abstract}
Resumo Os materiais empregados na pesquisa correspondem a rochas granulíticas, mais especificamente gnaisses enderbíticos. Exibem cor verde a cinza escuro, com textura de fina a média, e foliação de pouco a bem marcada. Todos estes corpos rochosos estão dispostos sob a forma de matacões. Os materiais estudados receberam as denominações de Verde Netuno, Verde Santa Cruz e Verde Choró, respectivamente para os gnaisses enderbíticos das regiões de Itapipoca, Granja e Chorozinho, região norte do estado do Ceará. A resposta aos ensaios tecnológicos mostra que eles apresentam boa qualidade para uso ornamental e de revestimento. Sobre estes aspectos, observou-se que as características petrográficas e os índices físicos (porosidade e absorção) são ferramentas muito importantes para a avaliação da durabilidade das rochas como rochas ornamentais. No contexto geral estas rochas mostraram-se bastante resistentes para uso como materiais de revestimentos.
\end{abstract}

Palavras-chave: Gnaisses Enderbíticos, Petrografia, Rochas Ornamentais.

\begin{abstract}
Petrography end technological characterization of enderbitic gneisses of the north portion of Ceará state for use as dimension stones. The materials employed in this research correspond to granulitic rocks, more specifically enderbitic gneisses. Those rocks exhibit of green to dark gray color, fine to medium texture and gentle to well-marked foliation. All these rocky bodies are arranged under the form of boulder. The denominations Green Netuno, Green Santa Cruz and Green Choró were given to the enderbitic gneisses of Itapipoca, Granja and Chorozinho, respectively. The results of the technological tests showed that these rocks present good quality for both ornamental and of coating use. On these aspects, it was possible to notice that both the petrographic characteristics and the physical parameters (porosity and absorption) are very important tools for the evaluation of the durability of the rocks as ornamental rocks. Therefore, in a general context the rocks studied are quite resistant regarding both to the alteration capacity and to the technological characteristics.
\end{abstract}

Keywords: Enderbitic Gneisses, Petrography, Dimension Stones.

INTRODUÇÃO O uso de rocha faz parte da história da civilização abrangendo obras em pedra das civilizações antigas, castelos da Idade Média até a Idade contemporânea e atualmente sua utilização principal como material empregado na construção de obras civis e monumentos, não somente pela sua abundância, mas pela sua resistência e durabilidade. A crescente demanda por rochas ornamentais e de revestimento, leva à pesquisa e caracterização de novos materiais rochosos com vista a uma contribuição para o desempenho do setor. O termo "granito", de uso generalizado na comercialização de rochas ornamentais, engloba tanto rochas ígneas, quanto metamórficas diversificadas, as quais diferem em suas propriedades físicas e mecânicas em função dos minerais presentes, relações texturais, grau de alteração etc. Neste sentido, os materiais utilizados nesse trabalho correspondem a três (3) litotipos de alto grau metamórfico (gnaisses em fácies granulito), cuja composição permite classifica-los como enderbitos (gnaisses enderbíticos). São materiais rochosos não explorados comercialmente e denominados de Verde Netuno, Verde Santa Cruz e Verde Choró, respectivamente provenientes das re- giões de Itapipoca, Granja e Chorozinho, região norte do estado do Ceará. Estes gnaisses enderbiticos foram selecionados dentre as variadas rochas encontrados nas respectivas regiões, por apresentarem características estéticas (cor e textura) aceitáveis para utilização no setor de rochas ornamentais. A pesquisa teve como objetivo a correlação das características petrográficas e tecnológicas dos gnaisses enderbíticos, envolvendo a determinação das características físicas e físico-mecânicas através dos índices físicos; a determinação da resistência à compressão uniaxial simples, ao módulo de ruptura, ao desgaste abrasivo pelo método Amsler, à dilatação térmica linear e à velocidade de ondas ultra-sônicas. Compara-se também os resultados obtidos nos ensaios de caracterização tecnológica com os parâmetros e as especificações sugeridas por Frazão \& Farjallat (1995) e com os da ASTM (C615), geralmente exigidos na qualificação dos materiais quando de sua aplicação no setor de rochas ornamentais e de revestimento para comercialização nos mercados interno e externo. Foram adotadas para o desenvolvimento da pesquisa, atividades envolvendo campo, laboratório e gabinete. Esses procedimentos visaram

1- UNESP, Departamento de Petrologia e Metalogenia/IGCE, Rio Claro (SP), Brasil. E-mail: annacostac@gmail.com

2 - Centro Federal de Educação Tecnológica do Rio Grande do Norte - CEFETRN, Natal (RN), Brasil. E-mail: anna.costa@cefetrn.br

3 - UFC, Departamento de Geologia/CC, Fortaleza (CE), Brasil. E-mail: nogueira@ufc.br. 
à caracterização geológica, petrográfica e tecnológica dos gnaisses enderbíticos.

CONTEXTO GEOLÓGICO O nordeste brasileiro vem sendo alvo de inúmeros trabalhos que têm como objetivo a definição de um arcabouço geotectônico em nível regional. A Província Borborema compreende uma extensa região com rochas de idade pré-cambriana, que cobrem uma superfície superior a $450.000 \mathrm{~km}^{2}$ do Nordeste Brasileiro, constituindo uma área de intensa complexidade litoestrutural e longa história geológica, desde a era Arqueana. Nesta Província, é marcante a atuação do ciclo Brasiliano/Pan-Africano (Neoproterozóico), caracterizada pelo intenso magmatismo granítico e desenvolvimento de extensas zonas de cisalhamento transcorrentes (Almeida et al. 1977). A Província Borborema tem sido recentemente dividida em domínios geotectônicos diversos, formando blocos crustais que foram amalgamados durante a orogênese (colagem) brasiliana (Santos 2003). Arthaud et al. (1998) propõem uma subdivisão para as unidades Pré-cambrianas aflorantes no Estado do Ceará, inclusas na porção setentrional da Província Borborema, reagrupando em cinco domínios baseados em critérios tectono-metamórficos. São eles os Domínios PiancóAlto Brígida, Jaguaribe-Orós, Ceará Central, Granjeiro e Noroeste do Ceará (Fig. 1). Neste contexto, a faixa granulítica de Granja (Fig. 1 Área 1) esta inseridas no Domínio Noroeste do Ceará, que exibe dois conjuntos de litotipos com associações mineralógicas caracterís-

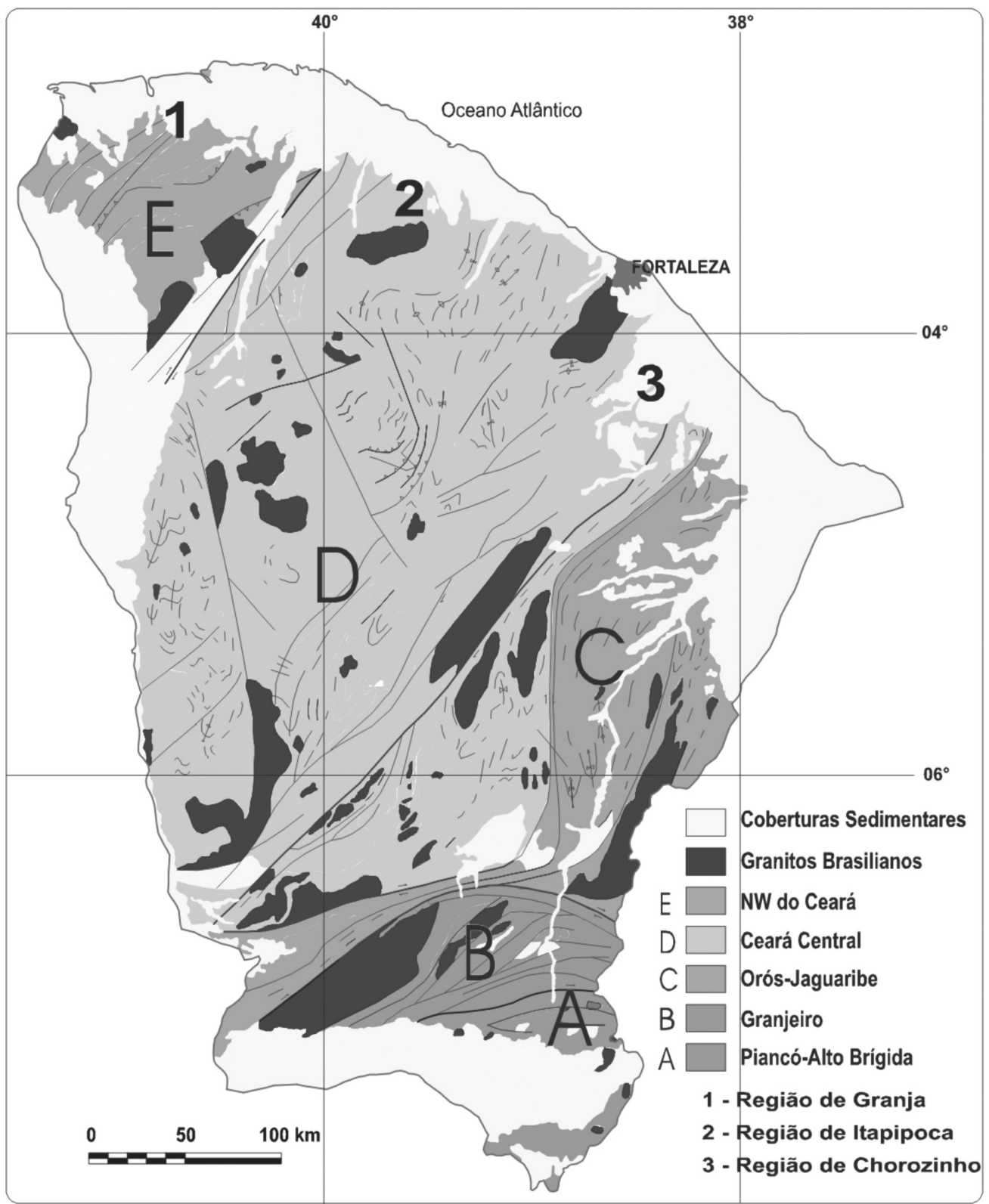

Figura 1 - Principais Domínios dos Terrenos Pré-Cambrianos do Estado do Ceará (Fonte: Arthaud et al. 1998) e as áreas de estudo: 1 - Região de Granja; 2 - Itapipoca e 3 - Chorozinho. 
ticas quanto à origem pré-metamórfica, gnaisse-khondalítico (silimanita-granada gnaisse) - paraderivado e charnockíto/enderbítico - ortoderivado (Nogueira Neto 2000). As faixas granulíticas de Itapipoca (Fig. 1 Área 2) estão inseridas no Domínio Ceará Central. Que inclui litologias representativas do Pré-Cambriano, não diferenciado, Proterozóico Médio e Superior, além do Terciário e Quaternário (Nascimento 2006), os litotipos encontrados incluem biotita gnaisses com hornblenda, granulitos (enderbitos e charnockitos/charnoenderbitos), granodioritos, monzogranitos, granodioritos com granadas, diques (sienogranitos) e coberturas colúvioaluvionares; e a região de Chorozinho (Fig. 1 Área 3) no Domínio Ceará Central, a região exibe uma seqüência de rochas metamórficas de alto grau, formadas por sillimanita-granada gnaisses, granada gnaisses, gnaisses enderbíticos e gonditos. O Estado do Ceará exibe uma diversidade de ambientes geológicos propícios a explotação de rochas ornamentais, cujo embasamento cristalino corresponde aproximadamente 75\% (110.000 $\mathrm{km}^{2}$ ) da superfície estadual. Destacam-se os "granitos" de modo geral, mármores, quartzitos, calcários, conglo- merados e arenitos conglomeráticos, rochas estas que em sua maioria apresentam um grande potencial como rochas ornamentais.

PETROGRAFIA O estudo petrográfico (aspectos mineralógicos, texturais e estruturais) é fundamental para a compreensão do comportamento físico-mecânico e de susceptibilidade à alteração dentre outras (Costa 2007). Portanto, quanto mais diversificados os métodos usados na investigação mineralógica, melhores serão as interpretações dos resultados de caracterização tecnológica, o que facilita a solução de problemas que por ventura venham a surgir antes, durante ou após a aplicação da rocha.

Verde Netuno - Gnaisse Enderbítico da Região de Itapipoca $\mathrm{O}$ gnaisse enderbítico apresenta-se na forma de matacões bastante deformados, mostrando em lâmina, processos de recristalização com recuperação em subgrãos de quartzo, biotita, e feldspatos com deslocamento de maclas, extinção ondulante e fraturas. Granulação média com grãos variando de 3 a 7 mm (Fig. 2a),
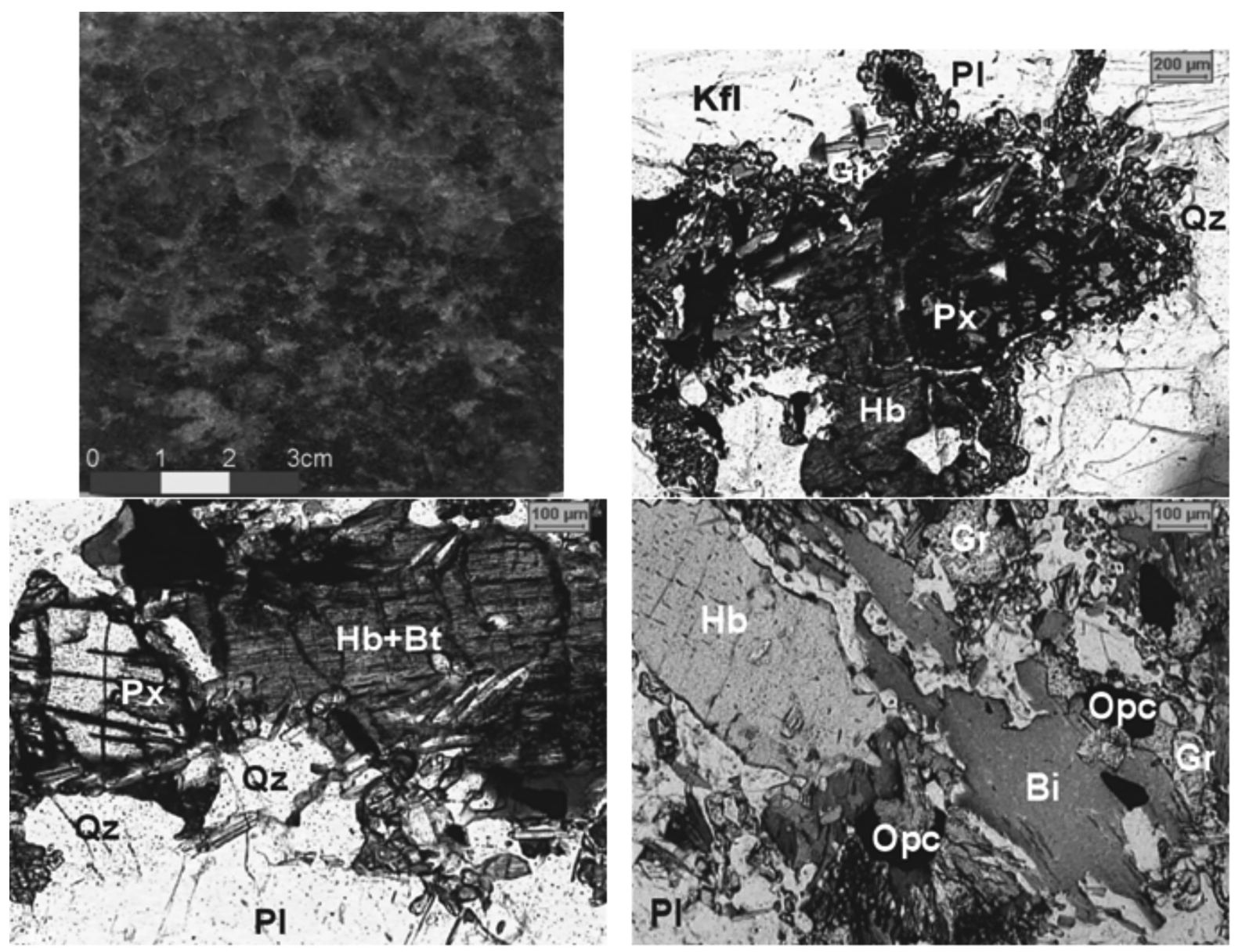

Figura 2 - Aspectos Petrográficos do Gnaisse Enderbítico Verde Netuno. a) Placa polida; b) Coroa de reação de granada (Gr) envolvendo piroxênio (Px), hornblenda (Hb) e biotita (Bt) - observação com luz natural; c) Relação de contato do piroxênio (Px), quartzo (Qz), plagioclásio (Pl) e a hornblenda (Hb) com clivagem preenchida por biotita (Bt) - observação com luz natural; d) Biotitas (Bt) delineando a foliação e Opacos (Opc) - observação com luz natural. 
textura do tipo granoblástica inequigranular e foliação marcada pelos minerais planares, micas, piroxênios e anfibólios. A associação mineral está representada por: plagioclásio $(32,5 \%)$ - feldspato potássico $(3,4 \%)-$ quartzo $(20,8 \%)$ - biotita $(17,3 \%)$ - piroxênios $(13,4 \%)$ - anfibólio (4\%) - granada (4,4\%), tendo como minerais acessórios a apatita, zircão e opacos $(4,2 \%)$.

No plagioclásio (oligoclásio-andesina) se destacam os contatos côncavo-serrilhado e plano-lobular com maclas segundo a lei da albita, por vezes constitui antipertitas . Também são encontrados megacristais de plagioclásios maclados. As microfissuras são evidentes e comumente acompanhadas por uma "massa de recristalização" intersticial, composta pelas alterações mais freqüentes que resultam em sericita (ocorrendo principalmente onde há uma maior recristalização) (Fig. 2b e 2c).

O feldspato potássico encontrado é o ortoclásio que ocorre em contato com o plagioclásio e/ou nas coroas de reação envolvendo granada, biotita e anfibólio. Quanto aos contatos, predomina o tipo côncavo-serrilhado indicando um bom entrelaçamento dos grãos.

$\mathrm{O}$ quartzo ocorre como agregados intersticiais registrando os processos tectônicos com extinção ondulante, bandas de deformação, estiramento de cristais e recristalização. Os contatos entre os grãos são de aproximadamente $90 \%$ do tipo côncavo-serrilhado denotando um bom entrelaçamento mineral (Fig. 2b e 2c).

A biotita apresenta-se como agregados lamelares amarronzados, juntamente com o quartzo e feldspato determinando a foliação tectônica, em íntima associação a relíctos de anfibólios e/ou como lamelas individuais em processos intermediários de cloritização (biotitas esverdeadas) (Fig. 2d).

Os piroxênios (clino e ortopiroxênios), por vez estão fraturados perpendiculares aos planos principais de clivagem, que em sua maioria estão preenchidas por opacos e/ou biotita (Fig. 2c). Ocorrem geralmente em contato com anfibólio, plagioclásio e granada.

$\mathrm{O}$ anfibólio (hornblenda) ocorre de forma semelhante aos piroxênios com os planos de clivagem preenchidos predominantemente por biotita, são de cor esverdeada a amarronzada (Fig. 2c), em sua maioria está formando coroas de reação envolvendo a biotita, granada e ortoclásio. Apresenta aproximadamente $80 \%$ de seus contatos do tipo irregular-serrilhado.

Os cristais de granada ocorre em sua maioria nas reações de desestabilização, dos piroxênios e plagioclásio. Quando presente em cristais apresenta-se bastante fraturada.

De um modo geral, está rocha apresenta grau de alteração fraco a médio, ou seja, as superfícies alteradas dos cristais estão entre $20 \%$ a $50 \%$, predominam os contatos do tipo côncavo-serrilhado e plano-lobular. Os microfissuramentos observados são do tipo intergrãos na ordem de 0,14 microfissuras $/ \mathrm{mm}^{2}$, e do tipo intragrãos ocorrem principalmente nos cristais de plagioclásio, quartzo, piroxênio e anfibólio, encontrando-se em sua maioria fechados ou preenchidos por materiais sericítico, biotítico e quartzoso, resultando na ordem de 2,05 microfissuras $/ \mathrm{mm}^{2}$.
Verde Santa Cruz - Gnaisse Enderbítico da Região de Granja Os gnaisses enderbíticos apresentam-se em corpos lenticulares com dimensões de aproximadamente $1 \mathrm{~km}$ de comprimento por $0,4 \mathrm{~km}$ de largura. Mesoscopicamente apresentam granulação média-fina com grãos que variam de 1 a $3 \mathrm{~mm}$ e cor verde escura a cinza (Fig. 3a). A textura dos enderbitos é granoblástica inequigranular. Estrutura bandada não é rara, quando presente mostra uma fina alternância, com limites pouco marcados, entre faixas compostas por Opx/Cpx + $\mathrm{Gr} \pm \mathrm{Bt} \pm \mathrm{Hb}$ e quartzo-feldspáticas (Fig. 3b, 3c, e 3d) (Nogueira Neto 2000). A associação mineral presente está representada por plagioclásio $(37,2 \%)$ - feldspato potássico $(1,5 \%)$ - quartzo $(24,6 \%)$ - biotita $(20,0 \%)-$ piroxênio $(4,4 \%)$ - anfibólio (5,0\%) - granada (4,2\%). Dentre os minerais acessórios está o zircão, a apatita e opacos compondo $3,1 \%$ da composição da rocha.

O plagioclásio (andesina) é a fase mineral mais abundante, comumente com o quartzo formam bandas félsicas nos enderbitos de foliação melhor marcada e nos enderbito de foliação pouco marcada, formam mosaicos com o predomínio de contatos côncavo-serrilhado. Apesar das diferenças estruturais da rocha, o plagioclásio apresenta, através de dados de microssonda, $\mathrm{An}_{30-35}$, não diferindo na composição.

O feldspato potássico é encontrado apenas em pequenas lamelas com intercrescimento anti-pertítico com o plagioclásio. Apenas foram quantificados 1,5\% de feldspato potássico e destes $80 \%$ apresentavam contatos do tipo côncavo-serrilhado e $20 \%$ plano-lobular.

Quanto ao quartzo constituinte das bandas, muitas vezes, se dispõem em ribbons de orientação concordante ou incipientemente oblíqua à foliação. Em meio ao mosaico, por vezes apresentam agregados recristalizados emoldurando grãos maiores do próprio quartzo e/ ou plagioclásio.

A biotita apresenta-se na forma prismática, de cor marrom a avermelhado indicando elevado teor de Ti em sua composição, predominam os contatos do tipo plano-lobular. Ocorre associada aos opacos, e em conjunto aos anfibólios e piroxênios formando uma foliação pouco pronunciada (Fig. 3c e 3d).

Os piroxênios (orto e clinopiroxênios) são encontrados individualmente e compondo a textura planar discreta da rocha. Apresentam-se em contatos com granada, anfibólio e/ou biotita, predominando os contatos dos tipos côncavo-serrilhado e plano-lobular. Apresentam concentrações ferruginosas em seus planos de clivagem, encontram-se bastante microfissurados com um grau de alteração médio a forte, por vez alterando para hornblenda.

O anfibólio (hornblenda), usualmente em contato com o piroxênio, se desenvolve em meio às fraturas, clivagem e/ou nas bodas deste mineral, predominando os contatos do tipo côncavo-serrilhado. Por vezes, encontram-se alterados para biotita, com um grau de alteração de médio a forte.

Os cristais de granada, em sua maioria, exibem textura de desestabilização, na qual simpléctitos e lamelas constituídas por ortopiroxênio e plagioclásio parecem surgir às expensas das granadas. Por vezes apre- 

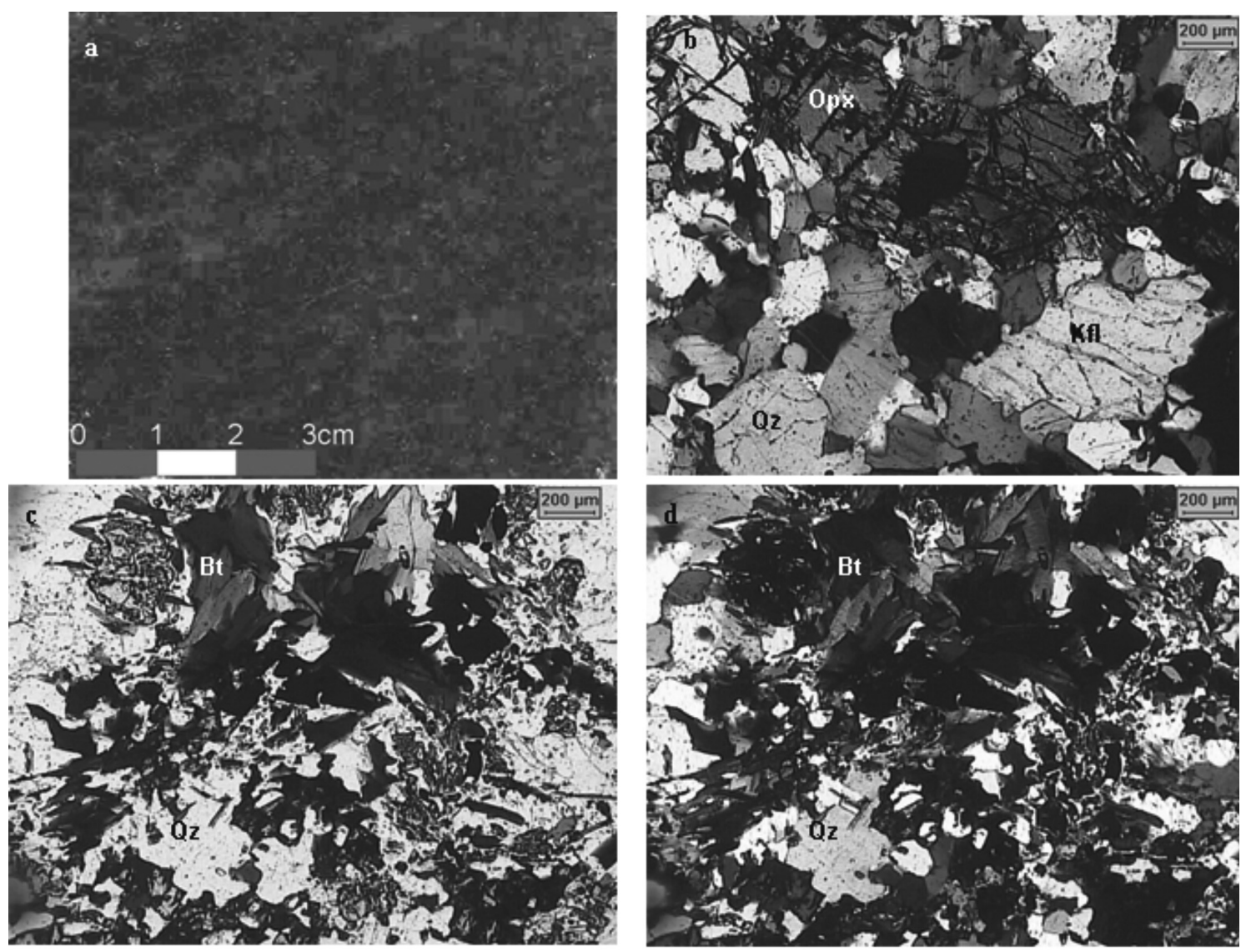

Figura 3 - Aspectos Petrográficos do Gnaisse Enderbitico Verde Santa Cruz. a) Aspecto macroscópico (placa polida); b) O piroxênio (Opx) é encontrado individualmente e compondo a textura planar discreta da rocha - observação com luz natural; c) Simplectitos e lamelas constituídas de ortopiroxênio (Opx) e plagioclásio (Pl), originadas à expensas de granada (Gr), e bordas de ortopiroxênio (Opx) em clinopiroxênio (Cpx) - observação com luz natural; d) Mesma feição da fotomicrografia 03 - observação Nicol Cruzado (NC).

sentam-se bordejando parcialmente o plagioclásio e os piroxênios exibindo o consumo quase total da granada.

Em geral o gnaisse enderbítico Verde Santa Cruz apresenta grau de alteração médio (com a superfície alterada do cristal entre $21-50 \%$ ), os contatos predominantes são dos tipos côncavo-serrilhado e planolobular. Não foi observado microfissuramento do tipo intergrãos, e o do tipo intragrão ocorre principalmente nos cristais de plagioclásio, mineral mais abundante na rocha. Normalmente estas microfissuras se encontram soldadas por material sericítico e as dos piroxênios estão preenchidas por biotita, estas atingem níveis elevados, resultando na ordem de 2,26 microfissuras $/ \mathrm{mm}^{2}$.

Verde Choró - Gnaisse Enderbítico da Região de Chorozinho Ocorrem sob a forma de maciços que variam entre 50 e 500 metros de extensão, com 5 a 15 metros de altura, em alguns locais ocorrem arrasados, sendo sua forma predominantemente elipsoidal. Correspondem a granulitos de composição intermediária, guardando relações de intrusões pretéritas com rochas paraderivadas (silimanita-granada gnaisses). Mesoscopicamente apresenta estrutura isotrópica à levemente foliada, cor verde escura a grafite e têm granulação média-fina a média, ou seja, os grãos variam de 1 a $7 \mathrm{~mm}$ (Fig. 4a). Ao microscópio exibem textura granoblástica inequigranular, com associação mineral: plagioclásio $(40,8 \%)$ - feldspato potássico $(2,8 \%)$ - quartzo $(11,8 \%)$ - biotita $(20,4 \%)$ - piroxênio $(7,0 \%)$ - anfibólio $(12,1 \%)$ - granada (2,0\%) (Fig. 4b). Os minerais acessórios presentes são: zircão, titanita, apatita e opacos $(3,1 \%)$.

Os plagioclásios (oligoclásio-andesina) são os minerais mais abundantes na rocha, em alguns cristais observam-se inclusões vermiculares de quartzo junto às bordas, em outros plagioclásios o quartzo é encontrado sob a forma de gotas mais ao centro. Apresenta subgrãos exibindo geminação segundo a lei Albita-Carlsbad (Fig. 4e).

O feldspato potássico por vezes forma intercrescimento pertítico e mirmequítico. Ocorrem freqüentemente microfissuramentos com preenchimento por mica branca. São observados ainda processos que envolvem recristalização com contatos em subgrãos, bem como deformações em geminações.

O quartzo está disperso por toda a seção sob a forma intersticial, ou em discretas bandas e na forma de 

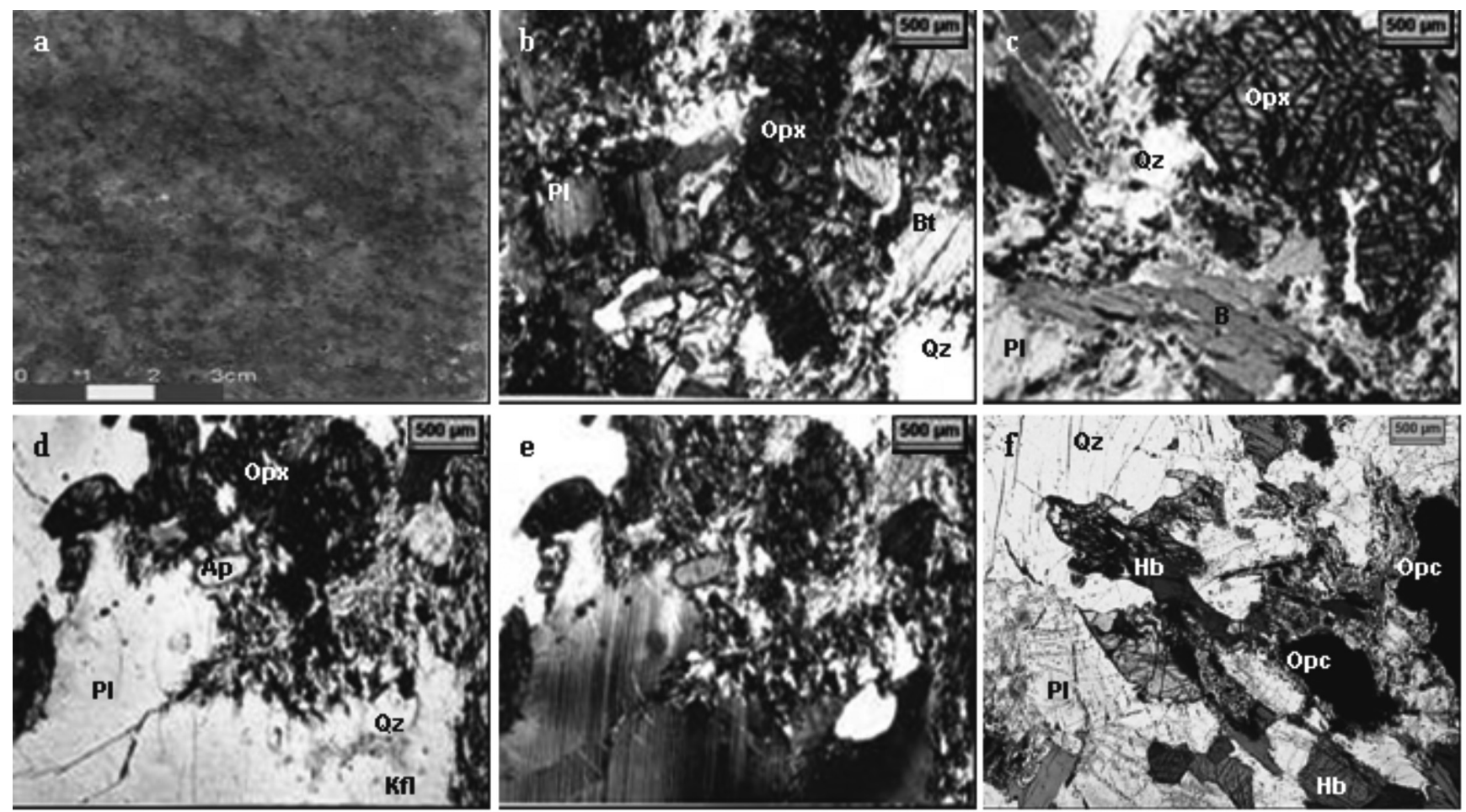

Figura 4 - Aspectos Petrográficos do Gnaisse Enderbitico Verde Choró. a) Aspecto macroscópico (placa polida); b) Enderbito exibindo textura granoblástica inequigranular. Ao centro ortopiroxênio (Opx) e biotita (Bt) +quartzo (Qz) - observação Nicol Cruzado; c) Associação mineral de ortopiroxênio (Opx), plagioclásio (Pl), biotita (Bt), quartzo $(Q z)$ e feldspato potássico (Kfl) - com luz natural; d) Reações de desestabilização da granada envolvendo biotita (Bt), hornblenda (Hb), ortopiroxênio (Opx) e plagioclásio(Pl) e feldspato potássico (Kfl), quartzo (Qz), apatita (Ap) - com luz natural; e) Idem a d - observação com Nicol Cruzado; f) Hornblenda compondo a foliação - com luz natural.

agregados granoblásticos. São pouco fraturados (Fig. $4 \mathrm{~d}$ e 4f) e registram extinção ondulante marcante.

Os piroxênios, geralmente possuem bordas de alteração, originando anfibólios (hornblendas). Os ortopiroxênios (opx) (hiperstênio) apresentam-se distribuídos na forma de grãos bem desenvolvidos bastante fraturados e envolvendo reações que sugerem dar origem à biotita. Dado que essas últimas podem ser visualizadas no interior dos cristais de ortopiroxênio, e por sua vez, o ortopiroxênio em relações de contato nas bordas das biotitas como que desequilibrando as mesmas (Fig. 4b, 4c e 4d). O clinopiroxênio (cpx) representados pelo diopsídio ocorrem como cristais tabulares.

A biotita apresenta-se em cristais de hábito lamelar, com inclusões de apatita e zircão. Em sua maioria as biotitas mostram cor e pleocroísmo característicos de cristais ricos em titânio (vermelho - marrom) e possuem pouca orientação.

O anfibólio (hornblenda) ocorre em contato com as biotitas e plagioclásio, apresentando cor variando de verde a amarronzada (Fig. 4f). Por algumas vezes aparecem dispostos entre as fraturas e/ou clivagens do orto e clinopiroxênio, o que sugere uma geração a partir destes.

Os cristais de granada apresentam-se bastante fraturados, são dispersas e ocorrem em reações de desestabilização envolvendo biotita, anfibólio, piroxênio e plagioclásio.
Em sua totalidade o enderbito Verde Choró apresenta grau de alteração fraco a médio (as superfícies alteradas dos cristais estão entre $20 \%$ a $50 \%$ ), predominam os contatos do tipo côncavo-serrilhado e plano-lobular. Os microfissuramentos do tipo intergrão são pouco pronunciados com freqüência de $0,07 \mathrm{mi}-$ crofissuras $/ \mathrm{mm}^{2}$, as fissuras do tipo intragrão ocorrem principalmente nos cristais de quartzo, plagioclásio, piroxênio, anfibólio e granada que normalmente se encontra soldadas por material sericítico, biotita e mais raramente por quartzo. Quantificadas todas as fissuras independentes do tamanho, resultaram na ordem de 3,6 microfissuras $/ \mathrm{mm}^{2}$.

As principais características petrográficas determinadas na análise macro e microscópicas encontramse resumidas na tabela 1 .

CARACTERIZAÇÃO TECNOLÓGICA A caracterização tecnológica de materiais para fins ornamentais e de revestimento é obtida através de análises e ensaios executados segundo procedimentos rigorosos, normatizados por entidades nacionais e internacionais (Tab. 2). Os resultados obtidos (Costa 2007) foram comparados aos parâmetros sugeridos por Frazão \& Farjallat (1995), e aos da ASTM C-615 (1992) (Tab. 3).

Nos índices físicos o Verde Netuno, Santa Cruz e Choró apresentam, respectivamente, massa especifica 
Tabela 1 - Síntese petrográfica dos gnaisses enderbíticos da porção norte do Estado do Ceará.

\begin{tabular}{|c|c|c|c|c|}
\hline \multicolumn{2}{|c|}{ PARÂMETROS AMOSTRA } & Verde Netuno & Verde Santa Cruz & Verde Choró \\
\hline \multicolumn{2}{|l|}{ Cor no estado seco } & Grafite a esverdeada & Cinza a esverdeada & Grafite \\
\hline \multicolumn{2}{|l|}{ Cor no estado úmido } & Esverdeada & Cinza escuro & Verde escuro \\
\hline \multicolumn{2}{|l|}{ Estruturas } & $\begin{array}{l}\text { Foliação bem marcada } \\
\text { por minerais planares. }\end{array}$ & Levemente bandada & Levemente bandada \\
\hline \multicolumn{2}{|l|}{ Textura } & $\begin{array}{l}\text { Granoblástica } \\
\text { inequigranular }\end{array}$ & $\begin{array}{l}\text { Granoblástica } \\
\text { inequigranular }\end{array}$ & $\begin{array}{l}\text { Granoblástica } \\
\text { inequigranular }\end{array}$ \\
\hline \multicolumn{2}{|l|}{ Granulação } & Média (>3-7mm) & Média-Fina (1-3mm) & $\begin{array}{l}\text { Média-Fina a média } \\
\qquad(1-7 \mathrm{~mm})\end{array}$ \\
\hline \multicolumn{2}{|l|}{ Natureza da rocha } & Ortoderivada & Ortoderivada & Ortoderivada \\
\hline \multicolumn{2}{|c|}{ Classificação da rocha } & Gnaisse enderbítico & Gnaisse enderbítico & Gnaisse enderbítico \\
\hline \multicolumn{2}{|l|}{ Minerais acessórios } & $\begin{array}{c}\text { zircão, apatita e opacos } \\
(4,2 \%)\end{array}$ & $\begin{array}{c}\text { zircão, apatita e opacos } \\
(3,1 \%)\end{array}$ & $\begin{array}{c}\text { zircão, apatita, titanita } \\
\text { e opacos }(3,1 \%)\end{array}$ \\
\hline \multicolumn{2}{|c|}{$\begin{array}{l}\text { IME - Índice de Minerais Escuros } \\
(\mathrm{Bt}+\mathrm{Gr}+\mathrm{Px}+\mathrm{Anf}+\mathrm{Min} \text { Acess })\end{array}$} & $43,3 \%$ & $36,70 \%$ & $44,60 \%$ \\
\hline \multicolumn{2}{|c|}{ Composição Modal (FK+Pl+Qz) } & $56,7 \%$ & 63,30 & $55,4 \%$ \\
\hline \multicolumn{2}{|c|}{ \% Feldspato Potássico (Kfl) } & 3,4 & 1,5 & 2,8 \\
\hline \multicolumn{2}{|c|}{ Contato côncavo-serrilhado (\%) } & 70 & 80 & 70 \\
\hline \multicolumn{2}{|c|}{ Contato plano-lobular (\%) } & 30 & 20 & 30 \\
\hline \multicolumn{2}{|c|}{ Grau de alteração } & 1 & 1 & 1 \\
\hline \multicolumn{2}{|l|}{ \% Plagioclásio (Pl) } & 32,5 & 37,2 & 40,8 \\
\hline \multicolumn{2}{|c|}{ Contato côncavo-serrilhado (\%) } & 60 & 60 & 10 \\
\hline \multicolumn{2}{|c|}{ Contato plano-lobular (\%) } & 40 & 40 & 90 \\
\hline \multicolumn{2}{|c|}{ Grau de alteração } & 1 & 1 & $1-2$ \\
\hline \multicolumn{2}{|l|}{ \% Quartzo (Qz) } & 20,8 & 24,6 & 11,8 \\
\hline \multicolumn{2}{|c|}{ Contato côncavo-serrilhado (\%) } & 90 & 50 & 40 \\
\hline \multicolumn{2}{|c|}{ Contato plano-lobular (\%) } & 10 & 50 & 60 \\
\hline \multicolumn{2}{|c|}{$\%$ Biotita $(\mathrm{Bt})$} & 17,3 & 20,0 & 20,4 \\
\hline \multicolumn{2}{|l|}{ Contato plano (\%) } & 40 & - & 30 \\
\hline Contato plano-serril & & 40 & 10 & 10 \\
\hline Contato côncavo-ser & o (\%) & 20 & - & 82 \\
\hline Contato plano-lobul & & - & 90 & 60 \\
\hline Grau de alteração & & 3 & 2 & 1 \\
\hline$\%$ Granada $(\mathrm{Gr})$ & & 4,4 & 4,2 & 2,0 \\
\hline Contato côncavo-ser & o $(\%)$ & 100 & 100 & 100 \\
\hline Grau de alteração & & 3 & $2-3$ & 3 \\
\hline \% Piroxênios (Px) & & 13,4 & 4,4 & 7,0 \\
\hline Contato irregular-se & o (\%) & - & 10 & - \\
\hline Contato plano-serril & & 30 & - & - \\
\hline Contato côncavo-ser & o (\%) & 20 & 50 & 80 \\
\hline Contato plano-lobul & & 50 & 40 & 20 \\
\hline Grau de alteração & & $2-3$ & $2-3$ & 1 \\
\hline \% Anfibólios (Anf) & & 4,0 & 5,0 & 12,1 \\
\hline Contato irregular-se & o (\%) & 80 & - & - \\
\hline Contato plano-serril & & 20 & - & - \\
\hline Contato côncavo-ser & o (\%) & - & 80 & 70 \\
\hline Contato plano-lobul & & - & 20 & 30 \\
\hline Grau de alteração & & $2-3$ & $2-3$ & 1 \\
\hline Microfissuras $/ \mathrm{mm}^{2}$ & Intergrão & 0,14 & 0,00 & 0,07 \\
\hline 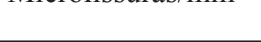 & Intragrão & 2,05 & 2,26 & 3,6 \\
\hline
\end{tabular}


Petrografia e caracterização tecnológica dos gnaisses enderbíticos da porção norte do estado do Ceará com aplicação no setor de rochas ornamentais

Tabela 2 - Resultados da caracterização tecnológica dos gnaisses enderbíticos da porção norte do Estado do Ceará.

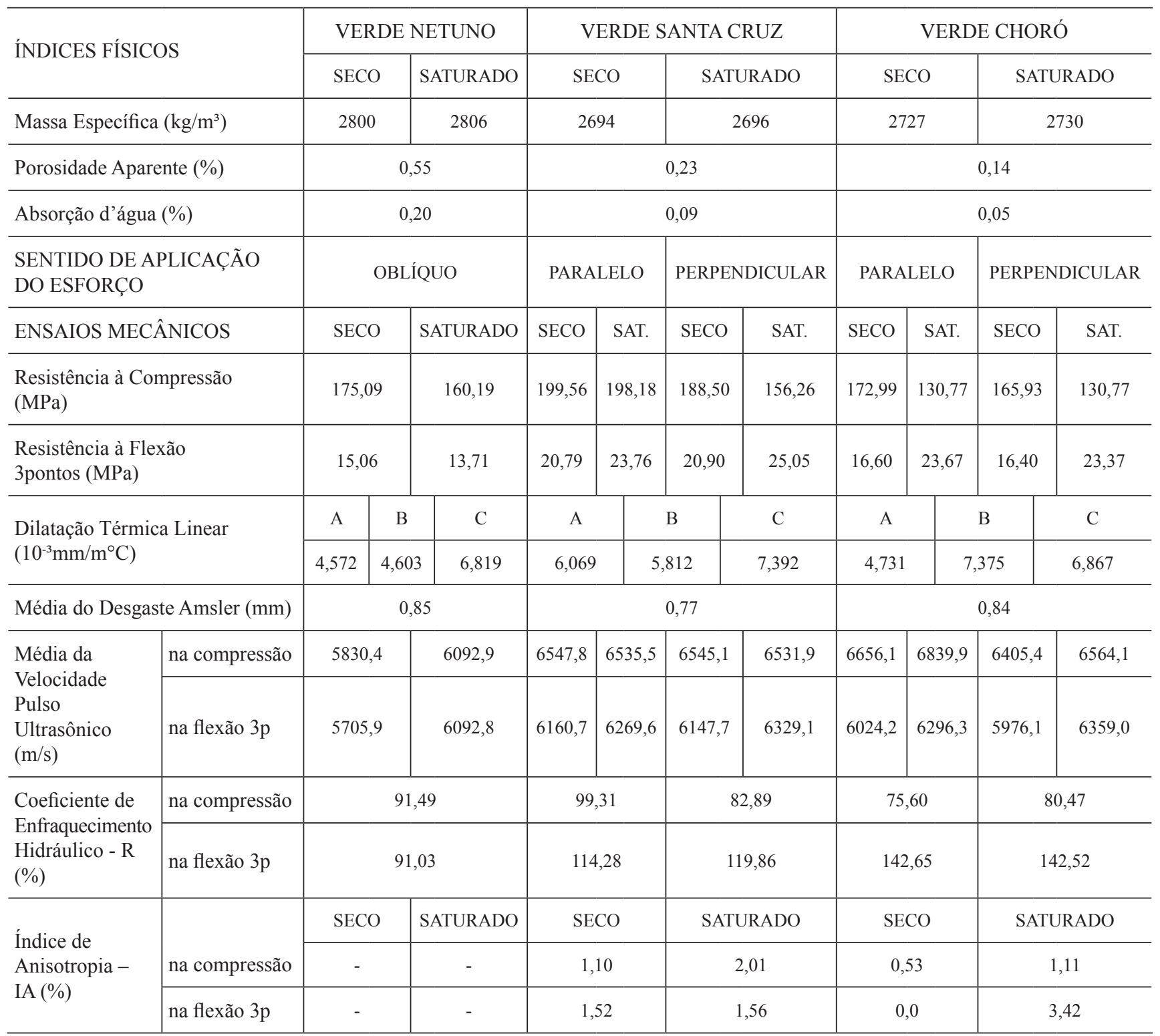

Tabela 3 - Comparação dos resultados da caracterização tecnológica dos gnaisses enderbíticos da porção norte do Estado do Ceará aos parâmetros sugeridos por Frazão \& Farjallat (1995), e aos da ASTM C-615 (1992).

\begin{tabular}{|c|c|c|c|c|c|}
\hline Ensaios $\quad$ Parâmetros & $\begin{array}{c}\text { Frazão \& } \\
\text { Farjallat (1995) }\end{array}$ & $\begin{array}{c}\text { ASTM } \\
\text { C } 615\end{array}$ & Verde Netuno & $\begin{array}{c}\text { Verde Santa } \\
\text { Cruz }\end{array}$ & Verde Choró \\
\hline Massa Específica Aparente seca $\left(\mathrm{Kg} / \mathrm{m}^{3}\right)$ & $>2550$ & $>2560$ & 2800 & 2694 & 2727 \\
\hline Porosidade Aparente (\%) & $<1,0$ & n.e. & 0,55 & 0,23 & 0,14 \\
\hline Absorção d'água (\%) & $<0,4$ & $<0,4$ & 0,20 & 0,09 & 0,05 \\
\hline Resistência à Compressão Uniaxial (Mpa) & $>100$ & $>131$ & $160-175$ & 156-199 & $130-172$ \\
\hline Resistência à Flexão de 3 pontos (Mpa) & $>10$ & $>10,3$ & $13-15$ & $20-25$ & $16-23$ \\
\hline Desgaste Amsler (mm) & $<1,0$ & n.e. & 0,85 & 0,77 & 0,84 \\
\hline Dilatação Térmica Linear $\left(10-^{3} \mathrm{X}\left[\mathrm{mm} /\left(\mathrm{m} .{ }^{\circ} \mathrm{C}\right)\right]\right)$ & $\leq 12,0$ & n.e. & $4,5-6,8$ & $5,8-7,3$ & $4,7-7,3$ \\
\hline Velocidade de Ondas Ultra-sônicas (m/s) & $>4000$ & n.e. & $5705-6092$ & $6147-6329$ & $5976-6359$ \\
\hline
\end{tabular}


aparente seca alta $\left(2800 \mathrm{~kg} / \mathrm{m}^{3} ; 2694 \mathrm{~kg} / \mathrm{m}^{3}\right.$ e $2727 \mathrm{~kg} /$ $\left.\mathrm{m}^{3}\right)$, baixa porosidade aparente $(0,55 \% ; 0,23 \%$ e 0,14 $\%)$ e baixo índice de absorção de água $(0,20 \% ; 0,09 \%$ e $0,05 \%$ ), e, basicamente, esses valores são controlados pela granulação e pela textura destas rochas. Os dados de massa específica, tanto em condições secas como em saturadas, apresentam valores muito próximos entre si, o que está condizente com os baixos valores da porosidade. Quando esses dados são comparados com o teor de minerais escuros (IME) de 43,3\%; 36,70\% e 44,6\%, para o Verde Netuno, o Santa Cruz e o Choró, respectivamente, verifica-se uma boa correlação entre ambos para cada tipo estudado. Os valores de porosidade e absorção de água são bastante distintos entre si. Eles se apresentam em escala decrescente, partindo do Verde Netuno, via Verde Santa Cruz, para o Verde Choró. Tal comportamento resulta da diferença na granulação, que varia de média para o primeiro e média-fina para os dois últimos, corroborado também pelo aspecto estrutural (foliação), que vai desde bem marcado no Verde Netuno a incipiente no Verde Santa Cruz. Quando se correlacionam os valores obtidos para os índices físicos e o número de microfissuras, observa-se que são inversamente proporcionais, o que caracteriza que, apesar de os materiais apresentarem grau de microfissuramento intragrãos elevado (respectivamente, de 2,05; 2,26 e 3,6 microfissuras $/ \mathrm{mm}^{2}$ para o Verde Netuno, o Santa Cruz e o Choró), o mesma não influenciam nessas propriedades. Isso porque a maioria dessas microfissuras é fechada e/ou preenchidas. O mesmo ocorre para as microfissuras intergrão. Da mesma maneira, não há uma correlação com os tipos de contatos, já que, para os três litotipos, predominam os dos tipos côncavo-serrilhado e plano-lobular. Concluímos, então, que para os gnaisses enderbíticos Verde Netuno, Santa Cruz e Choró a porosidade e absorção de água são controladas, basicamente, pela granulação e pela textura dessas rochas.

Os ensaios para a determinação da resistência mecânica (compressão uniaxial e flexão 3 pontos) foram efetuados nos estados seco e saturado, sendo que as variedades Verde Santa Cruz e Verde Choró os esforços foram aplicados ortogonal e paralelamente à foliação. Os valores obtidos não revelam maiores influências das condições analisadas (estados seco e saturado), pois oscilam entre os diferentes materiais, refletindo suas baixas capacidades de absorção de água. $\mathrm{O}$ mesmo é observado em relação à direção de aplicação dos esforços, o que reflete a discreta estruturação dos gnaisses enderbíticos.

A resistência ao desgaste abrasivo situa-se próxima aos valores limítrofes sugeridos por Frazão \& Farjallat (1995), oscilando entre $0,74 \mathrm{~mm}$ e $0,94 \mathrm{~mm}$. $\mathrm{Na}$ condição seca, o gnaisse enderbítico Verde Choró exibe desgaste abrasivo mais acentuado em relação aos demais gnaisses. Provavelmente isso de deve ao maior índice de minerais escuros $(44,6 \%)$, ao grau de alteração (1-2) e à menor quantidade de quartzo (11,8\%). Já o Verde Netuno exibe o menor desgaste, o que é reflexo dos valores relativamente menores do índice de minerais escuros $(43,3 \%)$, grau de alteração (1), e de um maior teor de quartzo $(20,8 \%)$. No gnaisse enderbítico
Verde Santa Cruz, observa-se uma relação mais marcante entre o teor de quartzo $(24,6 \%)$, um pouco mais elevado, e o valor mais baixo do desgaste $(0,80 \mathrm{~mm})$.

De um modo geral, quando saturadas, as rochas devem apresentar uma resistência menor à abrasão, pois está associada a sua porosidade e permeabilidade. No estado saturado, verifica-se que o gnaisse enderbítico Verde Netuno apresenta o maior valor de desgaste $(0,94 \mathrm{~mm})$, o que é, provavelmente, reflexo da sua granulação média (grãos de 3-7 mm) e, principalmente, pelo fato de apresentar os maiores valores de porosidade $(0,55 \%)$ e absorção de água $(0,20 \%)$.

No Verde Santa Cruz, ocorre uma pequena inversão no valor de desgaste no estado saturado $(0,74$ $\mathrm{mm}$ ), já que este material apresenta granulação médiafina (grãos de $1-3 \mathrm{~mm})$, porosidade $(0,23 \%)$ e absorção de água baixa $(0,09 \%)$. Destaca-se que os melhores valores correspondem aos do Verde Santa Cruz, reflexo da sua granulação média-fina e teor de quartzo pouco mais elevado em relação aos outros dois ganisses, corroborando resistência satisfatória para a utilização em pisos de ambientes com tráfego médio a alto.

Os resultados da dilatação térmica linear indicam que dentre os três gnaisses enderbíticos o Verde Santa Cruz $\left(6,424 \times 10^{-3} \mathrm{~mm} / \mathrm{m}^{\circ} \mathrm{C}\right)$ apresenta o melhor desempenho físico-mecânico, enquanto o menor dos valores foi registrado para o valor médio do Verde Netuno $\left(5,33 \times 10^{-3} \mathrm{~mm} / \mathrm{m}^{\circ} \mathrm{C}\right)$, que apresenta maior índice de porosidade $(0,55 \%)$ e de microfissuras intergrão $(0,14 / \mathrm{mm})$, menor teor de biotitas $(17,3 \%)$, e valores de velocidades de ondas ultra-sônica (5389 e $5124 \mathrm{~m} / \mathrm{s}$ ). Com valores intermediários está o Verde Choró (6,32 x $10^{-3} \mathrm{~mm} / \mathrm{m}^{\circ} \mathrm{C}$ ), que apesar de apresentar o maior número de microfissuras intragrão $(3,6 / \mathrm{mm})$, possui um teor de biotita $(20,4 \%)$ semelhante ao Verde Santa Cruz. Os valores de velocidade de propagação de ondas ultra-sônicas, tanto na condição seca (5124 a 6182 $\mathrm{m} / \mathrm{s}$ ) quanto na saturada (5104 a 6539,5 m/s), estão bem acima dos sugeridos por Frazão \& Farjallat (1995), ou seja, $>4.000 \mathrm{~m} / \mathrm{s}$ no estado seco. Isso indica que os materiais utilizados no ensaio de dilatação térmica linear não apresentam problemas estruturais ou de alterações que possam prejudicar e/ou interferir nos resultados, fornecendo mais uma ferramenta na avaliação do comportamento do material pétreo após sua dilatação e resfriamento.

CONCLUSÕES Os dados petrográficos dos gnaisses enderbíticos da porção norte do Estado do Ceará apresentam composição mineralógica e textural similar, exibindo textura granoblástica inequigranular, registrando associações com clinopiroxênio - ortopiroxênio - plagioclásio - hornblenda - granada - quartzo e coroas de reação em torno de granadas envolvidas por plagioclásios e piroxênios.

Quanto as características tecnológicas, estas rochas estão de acordo com os parâmetros sugeridos pela Americam Society for Testing and Materals - ASTM (C 615) e por Frazão \& Farjallat (1995).

As correlações estabelecidas entre as caracte- 
rísticas petrográficas e os parâmetros físicos demonstram que o comportamento dos gnaisses enderbíticos é diretamente controlado pelos aspectos composicionais, texturais e estruturais exibidos pelas rochas.

Conclui-se ainda que, para as rochas estudadas, há de se considerar, na realização dos ensaios, o estado estrutural dos materiais, particularmente na observação dos tipos de estruturações encontradas. De um modo geral, as características físico-mecânicas, aliadas ao aspecto estético, qualificam esses materiais para aplicação em ambientes exteriores e interiores como rochas ornamentais e de revestimento, tais como utilização em pisos de ambientes de alto tráfego, locais que ocorram variações de temperaturas (fachadas e piso) e apresentam resistência satisfatória, o que determina que não há restrições quanto a sua aplicação.

Agradecimentos Nossos agradecimentos à Fundação Cearense de Amparo à Pesquisa e Desenvolvimento Tecnológico (FUNCAP), por subvencionar o projeto P\&D n ${ }^{\circ} 411 / 02$ - Edital 003/02 e Conselho Nacional de Pesquisa - CNPq (proc. 140455/2003-5), pelo suporte financeiro dado ao desenvolvimento desta pesquisa.

\section{Referências}

Almeida F.F.M. de, Hasui Y., Brito Neves B.B. de, Fuck R.A. 1977. Províncias Estruturais Brasileiras. In: SBG, Simpósio de Geologia do Nordeste, 8, Campina Grande, Boletim Resumos, 6:363-391.

American Society for Testing and Materials (ASTM). 1992. Standard Specification for Granite Dimension Stone. ASTM C 615.

Arthaud M.H., Vasconcelos A.M., Nogueira Neto J.A., Oliveira F.V.C., Parente C.V., Monié P., Liegeois J.T., Caby R., Fetter A. 1998. Main structural features of Precambrian domains from Ceará (NE Brazil). In: International conference on Basement Tectonics, 14, Ouro PretoUFOP, Abstracts, p. 84-85.

Costa A.P.L. 2007. Alterabilidade e Caracterização Tecnológica dos Gnaisses Enderbiticos da Porção Norte do Estado do Ceará com Aplicação no Setor de Rochas Ornamental. Tese de Doutoramento, Instituto de Geociências, Universidade Estadual Paulista, Rio Claro, 214p.

Frazão E.B. \& Farjallat J.E.S. 1995. Caracterização das Principais Rochas Silicatadas Brasileiras Usadas como Pedras de Revestimento. In: Congresso Internacional de
Pedra Natural, 1, Lisboa-Portugal, p. 47-58.

Nascimento M.B. 2006. Petrografia, Química Mineral, Datação e Caracterização Tecnológica dos Granulitos da Região de Macaco - Itapipoca (CE). Dissertação de Mestrado, Programa Pós-Graduação em Geologia Regional, Universidade Federal do Ceará - UFC, Fortale$\mathrm{za} / \mathrm{CE}, 153 \mathrm{p}$.

Nogueira Neto, J. de A. 2000. Evolução Geodinâmica das Faixas Granuliticas de Granja e Cariré, estremo noroeste da Província Borborema. Tese de Doutoramento, Instituto de Geociência, Universidade Estadual Paulista, Rio Claro, 171p.

Santos A.A. 2003. Caracterização Litoestrutural e Geocronológica da Região Fósforo-uranífera de Itataia - CE. Dissertação de Mestrado, Curso de Pós-Graduação em Geologia, Universidade Federal do Ceará, 100p.

Manuscrito ID 9810

Submetido em 25 de novembro de 2007

Aceito em 20 de junho de 2008 Sistema eletrônico de submissão 